\title{
Correction to: Religious and Spiritual Practices Used by Children and Adolescents to Cope with Cancer
}

\author{
Lucas Rossato $^{1}$ (D) A Ana M. Ullán² · Fabio Scorsolini-Comin ${ }^{1}$
}

Published online: 26 June 2021

(c) Springer Science+Business Media, LLC, part of Springer Nature 2021

\section{Correction to: Journal of Religion and Health (2021) https://doi.org/10.1007/s10943-021-01256-z}

In the original publication of this article, Fig. 1 contains following errors:

1. The number of duplicate articles: The correct number of duplicate articles is: $(\mathrm{n}=280)$.

2. The number of selected for full reading: The correct number of articles is: $(n=195)$.

3. The number of excluded by full Reading: The correct information is given below:

Excluded by full reading $(n=175)$

Escaped the theme $(n=14)$; Other population $(n=75)$; Other publication format $(n=16)$; Repeated $(n=7)$; Language $(n=6)$; Theoretical Article $(n=13)$; Did not focus on R/S directly $(n=28)$; Not found $(n=5)$; Did not evidence the use of rituals/practices/object $(n=11)$.

The original article can be found online at https://doi.org/10.1007/s10943-021-01256-z.

Lucas Rossato

rossatousp@usp.br

1 Department of Psychiatric Nursing and Human Sciences, University of São Paulo At Ribeirão Preto College of Nursing, Av. Bandeirantes, 3900 - Vila Monte Alegre, Ribeirão Preto, SP 14040-902, Brazil

2 Advanced Research Unit in Pediatric Psychology, Department of Social Psychology and Anthropology, University of Salamanca, Salamanca, Spain 


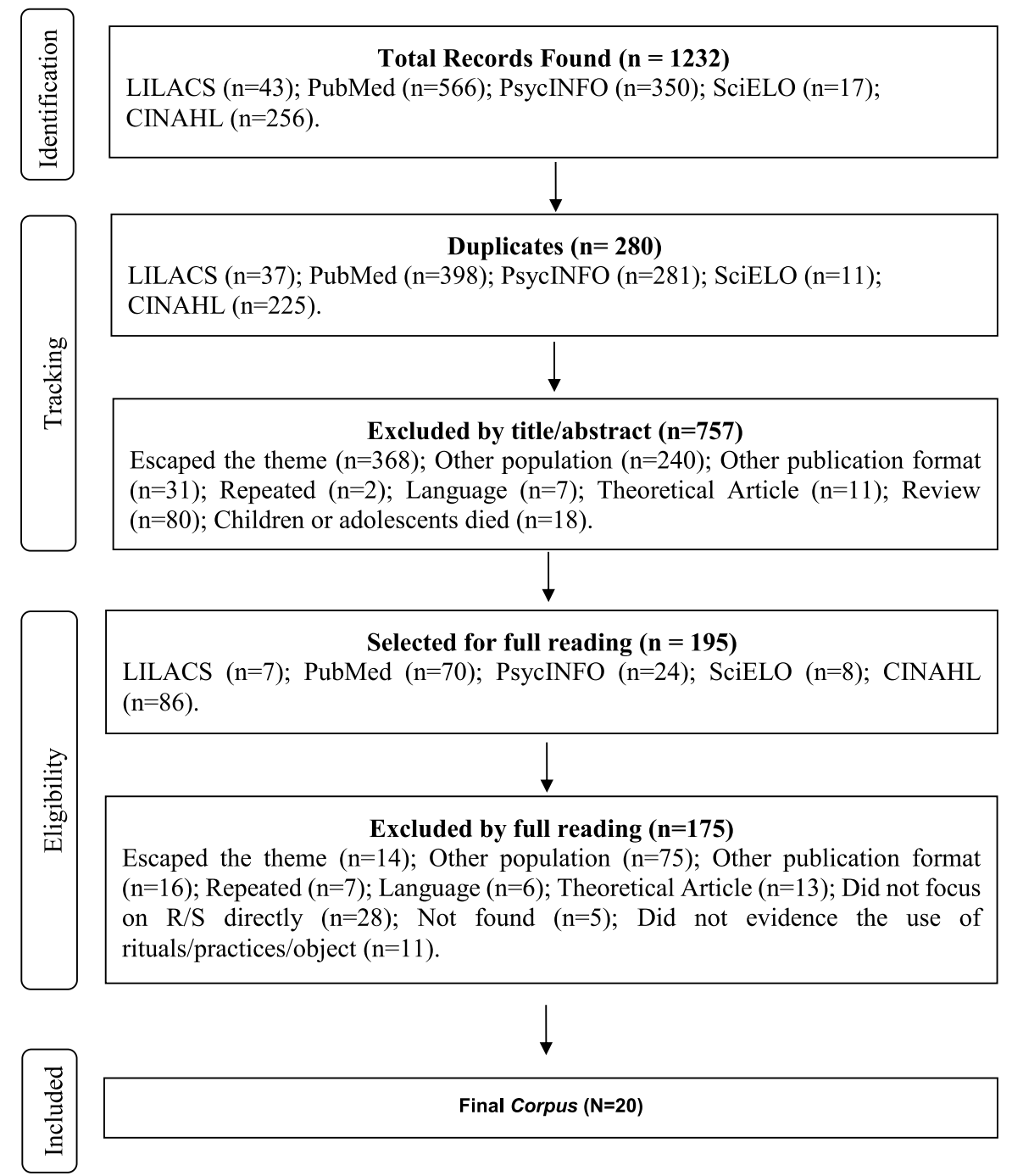

Fig. 1 Survey flowchart and article selection

Publisher's Note Springer Nature remains neutral with regard to jurisdictional claims in published maps and institutional affiliations. 